\title{
Study on the Opening Experiment Teaching for Undergraduates in Requirements of the Credit Management System
}

\author{
X.D. Yuan \\ Materials Science and Engineering Institute \\ Shandong Jianzhu University \\ Jinan, Shandong, China
}

\author{
G.L. Yuan \\ Jinan Engineering Quality and Work Safety Supervision \\ Station \\ Jinan, Shandong, China
}

\author{
X.J. Yang \\ Shandong Product Quality Inspection Research Institute \\ Ji'nan, China \\ Shandong Key Laboratory for Testing Technology of Material Chemical Safety \\ Ji’nan, China
}

\begin{abstract}
In requirements of the credit management system, the experimental resources were integrated by School of materials science and engineering, Shandong Jianzhu University, the opening experimental teaching system was established, and the experiment technical skills of students were improved. The influence of the opening experimental teaching system on the experiment technical ability of undergraduates was studied taking the failure analysis of ammonia-flume as an example, and reasons were also analyzed.
\end{abstract}

Keywords-experiment teaching; credit system; failure analysis; metallurgical structure inspection

\section{INTRODUCTION}

The credit system is a kind of the elective system. The study quantity of students was calculated by credits, and students can apply for graduate until they obtain certain credits.

The learning of students under credit system is elastic. They learn different courses and receive course credits. Students can apply for graduate until they obtain the lowest credits which satisfied the requirements of the school. Researches, including the personnel training mode, the teaching reform of school and professional, school enterprise cooperation and the reform of teaching practice were carried out by some colleges and universities in the "credit system" requirements [1-7].

Shandong Jianzhu University is a provincial university, in which engineering subjects are dominant, with balanced development of other subjects. The university began to try the student credit system management, and draw up educational objectives since 2012. Studies were carried out about the demand for technical personnel materials engineering in the new period combing the characteristics of the material science itself. The opening experiment teaching system was implemented relying on foundry cleaner production engineering technology research center of Shandong province and experimental teaching demonstration center, by which the experiment technical ability of undergraduates was improved.
In this paper, the influence of the opening experimental teaching system on the experiment technical ability of undergraduates was studied taking the failure analysis of ammonia-flume as an example, and reasons were also analyzed.

\section{IMPLEMENTATION OF THE OPENING EXPERIMENT TEACHING SYSTEM}

The opening experiment teaching system was implemented for one month. In this month, the experiment was designed by students independently, the equipment was operated by students independently, and the experimental data was deal with by students independently. The experiment scheme was designed by students according to practical problems encountered in the enterprise, and the new experiment project was applied for by themselves (they may receive the money, 2500 Yuan, from the school). Practical engineering problems can be solved through the experiment. Results can also be used to participate in a variety of national university science and technology competition, which leads to the improvement of students' employment competitiveness. The University subsidized student autonomous application topic more than 30 items each year, a total funding of research funds was more than 100000 Yuan. The ability to analyze the question, solve the problem, and hands-on activities was improved through the implementation of opening experiment teaching system. The specific experimental teaching mode was shown in Figure 1. 


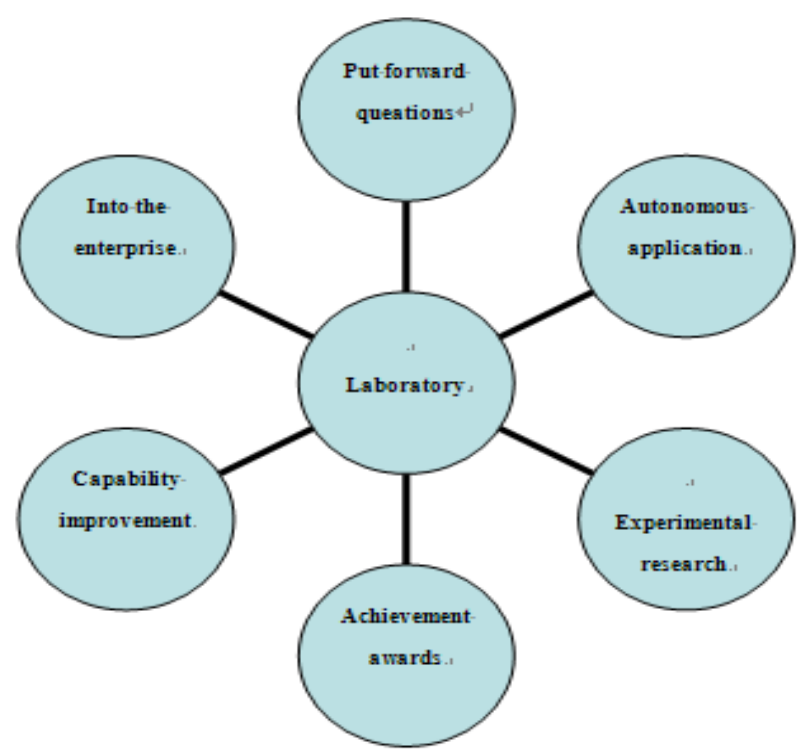

FIGURE I. MODE OF OPENING EXPERIMENT TEACHING SYSTEM.

\section{IMPROVEMENT OF EXPERIMENT TECHNICAL ABILITY OF UNDERGRADUATES}

\section{A. Objective and Methodology}

An ammonia water tank of the factory leaked in the process of using. The tank was made of steel Q235B plate. It was welded by seven steel plates. The temperature of ammonia water was 68 to $73{ }^{\circ} \mathrm{C}$.

The failure analysis of ammonia-flume was conducted by macro appearance observation, chemical composition analysis and metallurgical structure inspection.

\section{B. Macro Appearance Observation and Composition Analysis}

The illustration of the tank was shown in Figure 2. The leakage occurred in the parent metals. Macro-cracks can be observed. The composition was in accordance with the requirement of GB/T700-2006.

\begin{tabular}{|l|}
\hline The seventh floor \\
\hline The sixth floor \\
\hline The fifth floor \\
\hline The forth floor \\
\hline The third floor \\
\hline The second floor \\
\hline The first floor \\
\hline
\end{tabular}

FIGURE II. THE ILLUSTRATION OF THE TANK.

\section{Metallurgical Structure Inspection}

Samples were cut from two directions which were parallel to and ventricular to the weld seam. After mosaic, grinding and polishing, samples were observed by the optical microscope. It can be seen that there are some dendritic cracks as shown in Figure 3. After corrosion with $4 \%$ nitric acid alcohol, samples were observed by the optical microscope, the microstructure was shown in Figure 4. It can be seen from Figure 4 that there are some intergranular cracks and the cracks are close to the weld beads.

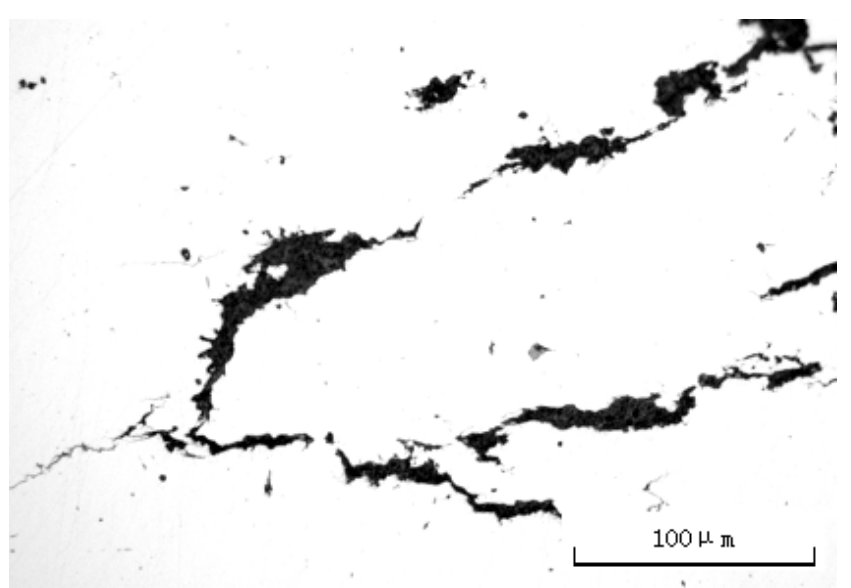

FIGURE III. DENDRITIC MORPHOLOGY OF THE CRACK.

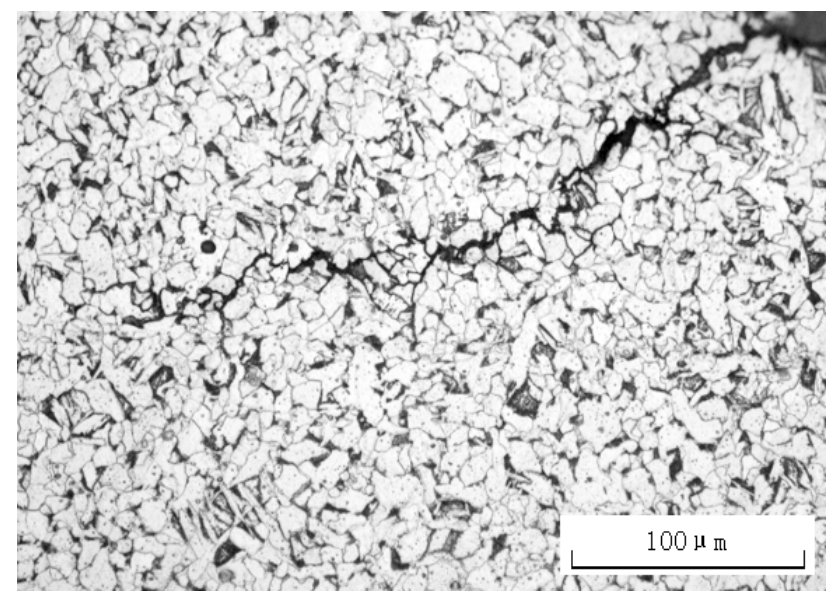

FIGURE IV. NTERGRANULAR CRACKS.

\section{Failure Analysis}

There are some dentric cracks in the leakage section of the parent metal, and cracks spread along the grains. It can be preliminarily concluded from those experimental data that stress corrosion occurred in the parent metal, which lead to the leakage of the tank.

It is well known that material factors, environmental factors and stress factors are the basic conditions of stress corrosion. In stress corrosion system, stress and corrosion are not the simple superposition, but promote each other. It is reported that carbon steels commonly suffer from stress corrosion in H2S solution, $\mathrm{NaOH}$ solution, nitric acid and nitrate solution [8]. A small amount of researches on the corrosion of carbon in ammonia were reported [9-10].

Tank bears only the action of gravity at work. It is expected that the stress, resulting in the leakage of the tank, comes from the pipe manufacturing and the welding stress.

It is reported that a protective film will be formed on the grain boundaries. However it is not stable and dissolves easily. 
Cracks will be generated along grain boundaries under stress, where the selective dissolving will occur and then stress corrosion happen leading to the leakage of the tank.

\section{CONCLUSIONS}

The opening experiment teaching system was implemented by the school of materials science and engineering of Shandong Jianzhu University since the implement of the credit system. The advantages of three-dimensional platform between the laboratory, the enterprise and the industry were fully developed. The experiment technical ability of undergraduate was improved, especially the ability of failure analysis.

\section{ACKNOWLEDGEMENT}

Sponsored by the Research Fund for the College science and technology plan of Shandong Province (Project No. J12LA11).

\section{REFERENCE}

[1] Chen S. Reform of practice teaching according to mode of applied cultivation [J]. Research and exploration in laboratory, 2012, 31(8):1-4.

[2] Zhao J H. Review of studies on the effectiveness of undergraduate experimental teaching in the west $[\mathrm{J}]$. Research and exploration in laboratory, 2012, 31(10):91-94.

[3] Zhang X M. Innovative research and practice on "project supermarket" mode of opening experiment [J]. Experimental technology and managemen, 2012, 29(10):33-36.

[4] Chen N N. Opening laboratory in engineering colleges and universities and reform of experiment teaching [J]. Experimental technology and management, 2006, 23(4):110-112.

[5] Lai Z H. On experimental teaching reform and practice of civil engineering major [J]. Research and exploration in laboratory, 2010, 29(11):319-321.

[6] Wang H Q, Wu Q F, Liang X J. Discussion on reform of university physics experiments by taking application as guidance. [J]. Experimental technology and management, 2012, 29(9):148-150.

[7] Liang L Y, Hu B L, Zhu L. Reform of experimental teaching for environmental engineering. [J]. Experimental technology and management, 2012, 29(9):126-129.

[8] Zhang Z. Study on Carbon Steel Sulfide Stress Corrosion Cracking Suspectibility in Refinery [D]. Dalian University of Technology: 2009. 3-4.

[9] Zhou Y L, Liu Q G. 3P_1402B cracking analysis of ammonia flume [J]. Physical Testing and Chemical Analysis Parta Physical Testing, 2002, 38(1): 565-567.

[10] Wang Y L, Yu Q. Analysis of leakage causes in circulating ammonia pipes and countermeasures. Anhui Metallurgy, 2010(2): 39-42. 